\title{
Requirement Analysis For Business Process Re-Engineering With Computational Intelligence
}

\author{
${ }^{1}$ Research Scholar, Bhagwant University, Rajasthan \\ ${ }^{2}$ Professor, CSE, Bhagwant Groups of Institutions \\ ${ }^{3}$ Joint Director, CDAC, Pune \\ ${ }^{4}$ Research Scholar, Poornima University, Jaipur, Rajasthan
}

Pooja Sharma ${ }^{1}$, Dr. Pusphneel Verma ${ }^{2}$, Chetan Sharma ${ }^{3}$, Amruta Surana ${ }^{4}$

Article History: Received: 11 January 2021; Accepted: 27 February 2021; Published online: 5 April 2021

\begin{abstract}
There are enormous software applications which are developed for the usage of the software users. The software user may be categorized as public users who use online services through internet, and the private users who use the specific software inside a specific organization only. The private users can be the business organizations, Educational institutions, Health care centers and other government organizations. Each organization has a specific requirement on the base of which the software and the customer relationship management frame work has to be designed. Organization specific software are developed, tested and delivered to the service users by the software development companies and where under maintenance by the development team in the timely manner. At times, when these registered users are in need of alterations and modifications in the software which are used, then the business process reengineering is required to be done. Thus business process reengineering plays a vital role in the maintainability and the sustainability of the software product based on the user requirement. To create an effective Business process Re-engineering Framework, the user (or) the stakeholder requirements are considered as the prerequisite. Based on the requirement the software product would be re-engineering, the stakeholders requirements has to be initially preprocessed and the stake holders has to be grouped and prioritized with the ranking of the requirement modules that has to be implemented. Finally the risk assessment has to be done to estimate the critical conditions or the changes that would be faced while reengineering and the requirements will be clustered for effective execution.
\end{abstract}

Keywords: Business Process Reengineering, Computer Intelligence, E-Commerce, Requirement Analysis.

\section{$1 \quad$ Introduction}

Business process is the collection of related tasks that has to be performed to produce a desired outcome or a service or a product for a particular customer. The business process activities are implemented in all the sectors of organization like business agencies, private and public organizations. The business process activities may be the set of tasks that has to be performed to create a product. These activities are generated by the customer's description and the product requirement. Due to the advent of the software automated techniques the user requirements can be analyzed and implemented to create a business product. Hence business process development is analogous to the software development process.

Software development process is the technique of splitting the software development procedures into sub modules, where each and every module will be performed as the distinct phase to improve the design, development and testing of the products and the projects. The software which is implemented can be reengineered for the purpose of change and reformation of the end user product. Reengineering refers to the process of transformation of the processing and procedures of the product development in the motive of improving the product quality to enhance the competitive advantages.

The business product which is developed will be estimated by the customers based on the product quality, price, and the availability to the users. The business product modeling has the ultimate aim of satisfying the customers and to provide a better service to the customer in all means. Hence the business product management team monitors the status and the responses of the user towards their product, hence the products has to be transformed and upgraded based on the users requirements to stand the competition in the market platform. Thus each and every business product needs to be reengineering based on the requirements of the users and it can also be upgraded or reengineered on the request of the business product maintenance team.

Reengineering is the process of reforming or redesigning the business process or the activities performed by the business product effectively for the purpose of improving and enhancing the quality, service and the cost of the product that would be visualized by the users. The business process can be represented as the set of task or activities that are formulated to execute to produce a product as per the requirement of the user. These business processes represents the work flow of the activities which are followed by the business product development team. Hence the stakeholder requirements play a vital role in the reengineering of the particular business product. 
Objective

The main aim of the proposed model is to

1. Design a business process reengineering model to effectively redesign the business model.

2. Implement the grouping of the stakeholders based on their specific requirements

3. Prioritization of the requirements based on the ratings and the ranking of the stakeholders

4. Computing the risk that has to be handled for the process of reengineering

5. Finally clustering of the requirements by the computational intelligent algorithms.

\section{Current Work and Preliminary Results}

Business Process Reengineering is the process of reforming and retransforming the business process in order to enhance the business product quality, speed and the availability of the product to the users. This business process modeling is so far used in the business transaction organizations like banking sectors and other customer transaction based organizations. The business processing modeling is so far done with the generated methodologies but they are not completely automated. The business process reengineering model is not implemented in the area of e-commerce applications. For computing the business process reengineering there are only fewer soft computing techniques which are implemented Hence the current business process reengineering model has to be integrated to work with the e-commerce applications. The e-commerce sites are the commercial sites where the commercial products are sold and purchased by the users over the internet. Due to the advent of the innovative technologies the customer who utilize the e-commerce sites expect those applications to be upgraded and updated timely and they expect those sites to be user friendly where they could access their product and utilize the site for their requirement. Usually the business process reengineering is a critical task due to its complexity; hence the major procedure to be reengineered can be automated by the implementation of soft computing techniques.

\section{WORK PLAN AND IMPLICATIONS}

To overcome the above mentioned issue and A Novel E-commerce Business Processing Reengineering framework is proposed. The ultimate aim of the proposed framework is to create an automated machine learning model which would suggest the reengineering procedures to be done in the shorter time duration. Initially the input for the process reengineering is the stakeholder's requirements which are to be updated for the improvement of the product. The stakeholder are grouped based on the Specific Requirement Based Stakeholders Grouping Algorithm and requirements are analyzed and prioritized based on the Rating Based Requirement Prioritization Algorithm. Further the requirements are grouped based on the Similarity based Requirement Consolidation Algorithm. Then from the consolidated requirements the correlation based risk estimation is done to categorize the requirement as critical and significant requirements. Finally requirements are published based on the Novel Fuzzy based Reengineering Algorithm. The proposed model will be outperforming than all other existing techniques.

- $\quad$ The proposed research has to be implemented to create a novel reengineering model to be applicable for the e-commerce systems.

- $\quad$ To perform the business process modeling with the help of an automated soft computing techniques.

- $\quad$ To prepare an effective reengineering model that will perform computations with less time complexities. 
Flow Diagram

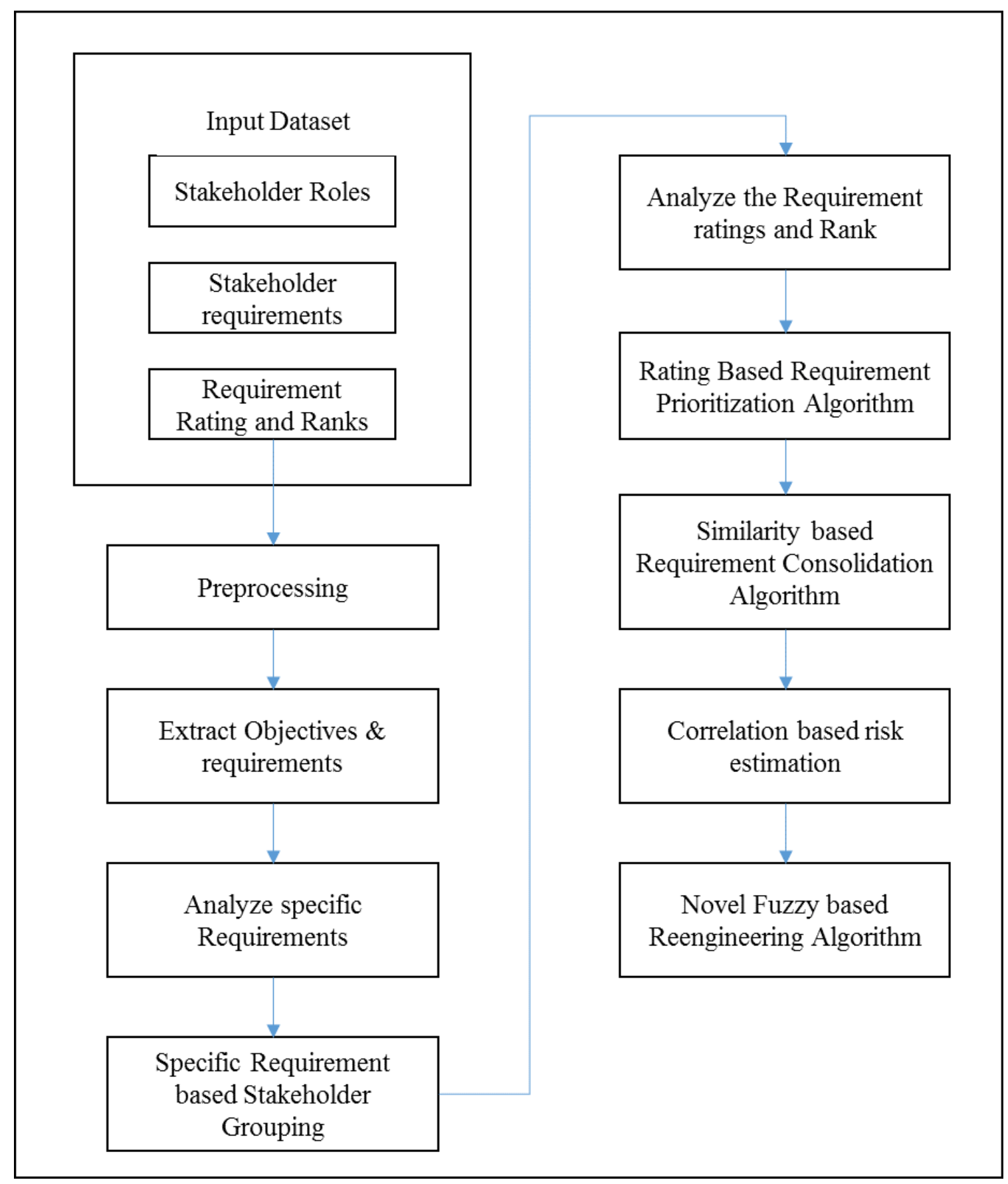

\section{References}

1. D.Y. Wang, L.W. Pan, L. Lu, J.P. Zhu, G. X. Liao,"Emergency Management Business Process Reengineering and Integrated Emergency Response System Structure Design for a City in China", Procedia Engineering 52 (2013) 371 - 376.

2. Distante, D., Garrido, A., Camelier-Carvajal, J. et al., "Business Processes Refactoring to Improve Usability in E-Commerce Applications", Electron Communication Research (2014) 14: 49 
3. RohitMehra, VinayakNaik, Rahul Purandare, Kapish Malik, "KIRKE: Re-engineering of Web Applications to Mobile Apps", MOBIQUITOUS '16, November 28-December 01, 2016, Hiroshima, Japan

4. Nikolaos A. Panayiotou, Sotiris P. Gayialis, "A business process modeling-enabled requirements engineering framework for ERP implementation", National Technical University of Athenes January 2016

5. AdsonCarmo, Marcelo Fantinato, Lucin'eia Thom, Edmir Prado, Mauro Spinola, Patrick Hung, "An Analysis of Strategic Goals and Non-Functional Requirements in Business Process Management", ICIES April 2017

6. Sanjay Mohapatra, AnupamChoudhury, K. Ganesh, "Framework for supporting 'business process reengineering'-based business models",Int. J. Business Innovation and Research, 2017, 085102

7. Mahmoud AbdEllatif, Marwa Salah Farhan, Naglaasaeedshehata, "Overcoming Business Process Reengineering Obstacles Using Ontology-based knowledge Map Methodology”, Future Computing and Informatics Journal, 10 October 2017

8. K.H. Leung, K.L. Choy, Paul K.Y. Siu, G.T.S. Ho, H.Y. Lam, CarmanK.M.Lee, "A B2C e- commerce intelligent system for re-engineering the e-order fulfilment process", Expert Systems with Applications 91(2018) 386-401

9. Gholamreza Jamali, Mohammad Ali Abbaszadeh, MehranEbrahimi, and Tahereh Maleki, "Business Process Reengineering Implementation: Developing a Causal Model of Critical Success Factors" International Journal of e-Education, e-Business, e-Management and e-Learning, vol. 1, No. 5, December 2011. 